\title{
Phenomenal characteristics of guided imagery, natural imagery, and autobiographical memories
}

\author{
KATHERINE D. ARBUTHNOTT, CARLA B. GEELEN, and KINDA L. K. KEALY \\ University of Regina, Regina, Saskatchewan, Canada
}

\begin{abstract}
Research indicates that guided imagery experiences can be mistaken for actual experiences under some circumstances. One explanation for such effects is that memory representations of guided imagery and actual events contain similar phenomenal characteristicssuch as sensory and contextual details, making the source of the events less distinguishable. This study examined this prediction, comparing memory characteristic ratings for guided imagery experiences with those for memories of perceived and natural imagery events (e.g., fantasies). Results replicated previous findings for the difference between perceived and natural imagery memories. Guided imagery ratings were also lower than those for perceived memories for most sensory details (sound, smell, and taste) and temporal details. However, guided imagery ratings for reflective details were lower than both perceived and natural imagery memory ratings. Thus, guided imagery was similar to natural imagery with respect to sensory details, but similar to perceived memories with respect to reflective details.
\end{abstract}

In general, humans are quite good at discriminating between memories for actual and imagined events. Most of the time we are not prone to confusion between our Walter Mitty-esque ${ }^{1}$ fantasies and the events of our lives. However, both experience and research indicate that we are not perfect at such discrimination. Under some circumstances, individuals show confusion between imagined and actual events. In particular, guided imagery events are sometimes mistaken for actual experiences (see Arbuthnott, Arbuthnott, \& Rossiter, 2001 for a review), a phenomenon that is of particular concern for debates about the likelihood of implanting false memories of childhood trauma using therapeutic imagery techniques (e.g., Brown, Scheflin, \& Hammond, 1998; Ceci \& Loftus, 1994; Lindsay \& Briere, 1997).

Johnson's reality-monitoring framework (Johnson, 1991; Johnson \& Raye, 1981) suggests that such misattributions are caused by the interaction between two factors: (1) memory representations that are atypical of their class (i.e., perceptually experienced vs. mentally generated events such as thoughts or fantasies) and (2) judgment processes that make use of such representational differences. Specifically, two main types of information facilitate discrimination between memories of perceived and imagined events: the quality and amount of perceptual (e.g., sensory, contextual) detail and reflective information (e.g., planning, decision making) associated with a

This work was supported by a grant from the Natural Sciences and Engineering Research Council of Canada to K.D.A. We thank Richard Marsh, Karen Mitchell, ChristopherHeaps, and Gabriel Radvansky for their helpful comments on earlier versions of this manuscript. Correspondence should be addressed to K. Arbuthnott, Department of Psychology, University of Regina, Regina, SK, S4S 0A2 Canada (e-mail: katherine.arbuthnott@uregina.ca). memory for the original event. Memories of events with a perceptual origin would typically contain more perceptual and contextual detail, whereas events that were mentally generated would typically contain more details about reflective or cognitive operations. Although the criteria and efficiency of judgment processes are central to the reality-monitoring framework (e.g., Johnson, Hashtroudi, \& Lindsay, 1993), the focus of the present study was on the phenomenal quality of memory representations. Given the misattribution effects associated with guided imagery, it is important to determine whether guided imagery typically results in memory representations with characteristics more similar to those of perceived than to those of imagined events.

Reports of the phenomenal characteristics of memories for perceived and imagined events support the representational hypotheses of the reality-monitoring framework (Johnson, Foley, Suengas, \& Raye, 1988; McGinnis \& Roberts, 1996). For example, Johnson et al. (1988) had participants recall one memory of a perceived event from their history, and one memory of a mentally generated event, such as a fantasy or unfulfilled intention. Participants then rated the phenomenal characteristics of these memories using a 39-item Memory Characteristics Questionnaire (MCQ). As predicted, memories of perceived events were reported to have more perceptual and contextual information (i.e., time and location details) than were memories of imagined events. The same pattern of results was observed comparing staged (i.e., perceived) events with imagined events that were generated using guided imagery scripts (Suengas \& Johnson, 1988).

The reality-monitoring framework also predicts that the degree of effort required to generate imagined events influences their discriminability from perceived events (Johnson, 1991; Johnson, Kahan, \& Raye, 1984; John- 
son, Raye, Wang, \& Taylor, 1979). Imagined events that require more effort would have more information about the reflection involved in generating that event, and thus would be less likely to be mistaken for a perceived event. Several studies support this hypothesis. For example, Johnson et al. (1984) had people who lived together report actual or made up dreams to each other, and then attempt to distinguish between their own and their partner's reports. Given the extra mental effort required to make up a dream, the researchers predicted that participants would be more accurate in distinguishing made up dreams, and this was observed. Similarly, Finke, Johnson, and Shyi (1988) observed that more easily generated visual images were confused with perceptions more often than difficult-to-generate images, and Durso and Johnson (1980) observed that spontaneous images were more likely to be confused with percepts than with explicitly generated images.

This research suggests that any manipulation that increases the similarity of perceptual or reflective detail between perceived and imagined events is likely to increase reality-monitoring errors (i.e., confusing imagined events with perceived events). As Johnson (1991) stated, "Disrupted reality monitoring would result from any circumstance that decreases differences between phenomenal qualities of perceived and imagined events such as unusually vivid imagery or reduced cognitive operations associated with imagined information" (Johnson, 1991, p. 7). ${ }^{2}$

Recently there has been considerable concern that the practice of guided imagery creates imagined memories that are less distinguishable from perceived memories than are typical mentally generated experiences such as dreams or fantasies (henceforth referred to as natural imagery). Specifically, it is claimed that guided imagery used in psychotherapy results in false memories, including mistaken memories of childhood trauma (Garry \& Polaschek, 2000; Goff \& Roediger, 1998; Lindsay \& Read, 1994; Loftus, 1997; Shobe \& Schooler, in press). Several studies have shown that imagery increases reports of "recall" for a suggested childhood event that was not actually experienced, both in adults (Heaps \& Nash, 2001; Hyman \& Pentland, 1996) and in children (Pezdek $\&$ Hodge, 1999), at least when the suggested false event is plausible. One potential cause of such misattribution errors may be the phenomenal characteristics associated with the imagined events.

Guided imagery events are often scripted, with the script read to an individual while he/she imagines the suggested images and scenarios, frequently while he/she is in a state of relaxation (e.g., Hall, 1990). It is possible that such guided imaginings would require less planning and effort than other types of thoughts or fantasies (i.e., natural imagery), reducing their difference from perceived events with respect to reflective operations. Specifically, imagining scenarios in response to a guided imagery script would require only compliance with the instructions, bringing to mind the suggested scene or action, in contrast to self-generated thoughts, which would require initiating or selecting the topic of thought as well as generating the content. Thus, on the continuum of internalexternal source of an experience, guided imagery would be intermediate to perceived events and natural imagery, with an external suggestion for the event theme but internal generation of the specific details. This may result in less memory for reflective characteristics, promoting attribution errors similar to those observed with other low-effort imagined events (Finke et al., 1988; Johnson et al., 1984). Furthermore, many guided imagery scripts deliberately focus on sensory characteristics, drawing an imager's attention to the visual, auditory, and kinesthetic characteristics in their imagined event. Thus, guided images may result in both greater perceptual detail, and less reflective effort than natural imagery, circumstances under which reality-monitoring discrimination is thought to be less accurate.

It is thus important to examine the similarity of guided imagery and perceived memory representations as a possible cause of memory misattributions. Although sparse, the existing evidence suggests that memory representations of guided imagery events are different from those of perceived memories with respect to phenomenal characteristics, both for isolated words (i.e., the Deese paradigm, Mather, Henkel, \& Johnson, 1997) and for events (Heaps \& Nash, 2001; Suengas \& Johnson, 1988). Suengas and Johnson compared the phenomenal characteristics of memories for simple events (e.g., having coffee and cookies with the experimenters; introducing oneself) that were either enacted or imagined in response to guided imagery scripts. Clear distinctions between perceived and guided events were observed, both initially and after delays of 1 or 2 days. Recently, Heaps and Nash (2001) observed that the memory characteristics of false recollections that were generated using imagery could be distinguished from those of true memories. Relative to true memories, false recollections were rated as being less detailed, less emotionally intense, and less important. Despite these differences in memory characteristics, however, participants mistakenly believed that their false recollections were autobiographical events (see also Henkel, Franklin, \& Johnson, 2000), indicating that these phenomenal differences may be insufficient to guide accurate reality monitoring, at least when another person endorses the misattributed event as a memory.

The purpose of the present study was to compare the phenomenal characteristics of guided imagery, natural imagery, and perceived memories in a single study. Although the existing evidence suggests that memory representations of guided imagery and perceived events are different phenomenologically, these differences may not support distinction between them (Heaps \& Nash, 2001; Henkel et al., 2000), perhaps because guided imagery representations are too different from typical mentally generated representations (i.e., natural imagery) to be identified as imagined. 


\section{METHOD}

\section{Participants}

Fifty participants ( 35 women) were recruited through the participant pool operated by the Department of Psychology at the University of Regina and were given course credit in undergraduate psychology courses in exchange for their participation. Participants ranged in age from 18 to 49 years $(M=23.8, S D=7.9)$. The study took approximately $40 \mathrm{~min}$ for each participant to complete.

\section{Materials and Procedure}

Each participant was asked to recall two memories, one perceived and one natural imagery event, and to participate in one guided imagery experience (see Appendix A for stimuli). The prompts for the perceived and natural imagery events were essentially the same as those used by Johnson et al. (1988): In the perceived condition participants were asked to recall (1) a visit to a library, (2) a visit to a dentist or doctor, or (3) a social occasion. In the natural imagery condition they were asked to recall (1) a fantasy, (2) a dream, or (3) an unfulf illed intention. The guided imagery scripts were adapted from previous research (Garry, Manning, Loftus, \& Sherman, 1996; Heaps \& Nash, 1999). Scripts included (1) shaking hands with the prime minister, (2) finding \$10 in a parking lot, and (3) breaking a window with one's hand. The specific memory prompts and script assigned to an individual participant were randomly determined, with the constraint that all possible combinations were tested across participants. Similarly, the order of memory events (perceived, natural imagery, guided imagery) was counterbalanced across participants. Following each recall or imagery event, participants completed the MCQ (Johnson et al., 1988; see Appendix B) for that event. For each question of the MCQ, participants rated their experience using a 7-point scale ranging from weakly (1) to strongly (7) experienced memory characteristics.

Memory prompts were presented as in Johnson et al. (1988; see Appendix A). Guided imagery scripts were narrated by the experimenter and participants were instructed to picture the event as clearly and completely as possible. As in Hyman and Pentland (1996), participants were told that closing their eyes, and including familiar places, people, and things, in the imagined event might help them to form a more complete mental picture. Each guided imagery script was presented in two parts to enable elaboration of the image (Garry et al., 1996; Heaps \& Nash, 1999). First, the experimenter read a description of the setting and initial details of the event, and participants were given approximately $1 \mathrm{~min}$ to form a complete mental image. They were then asked a question about their imagination of the event (see Appendix A), with the suggestion that the question would help them imagine the event more completely. Once they had written their response to the question, a description of the action of the event was read. Participants were given another minute to complete the mental image, and were then asked another question, to which they wrote their response. Following this, they completed the MCQ for the guided imagery event.

Half of the participants were asked to recall memories and imagine guided imagery events in an adult context, and half completed these tasks in a childhood context (under 12 years of age). Participants were tested singly or in pairs, and each participant pair was randomly assigned to the adult and childhood conditions.

\section{RESULTS}

Adult condition participants estimated that $96.2 \%$ of the perceived and $92.3 \%$ of the imagined memories had occurred within the last year. The literal answer to this question for the guided imagery condition would have been "today," and $34.6 \%$ of participants responded in this way. The majority $(57.7 \%)$ responded "within the past year," suggesting that they interpreted this question to refer to the time at which they imagined the guided imagery event occurring, rather than the time at which the event was suggested to them. In the childhood condition, participants estimated their age for perceived memories at a mean of 8.3 years $(S D=2.7$, range $=4-14$ years $)$, and their age for natural imagery memories at 9.8 years $(S D=2.5$, range $=5-17$ years $)$. Participants imagined themselves experiencing the guided imagery event at a mean of 8.2 years $(S D=1.8$, range $=5-12$ years; 7 participants did not respond to this question for guided imagery).

The MCQ ratings were categorized according to systems used in previous research (McGinnis \& Roberts, 1996; Suengas \& Johnson, 1988), resulting in seven phenomenal measures (see Appendix C for the specific MCQ question assignments; not all MCQ questions were included in the seven categories). The mean ratings for each MCQ category, by memory type and age condition, are presented in Table 1 . These ratings were analyzed using 3 (memory type: perceived, natural imagery, guided imagery) $\times 2$ (age condition: adult, childhood) mixed factor analyses of variance (ANOVAs) for each MCQ category. Post hoc analyses were conducted using Tukey's honestly significant difference (HSD). The order of presentation is as follows: First, the results for the overall ANOVAs are reported, followed by the contrasts between perceived and natural imagery events. These comparisons were examined to determine whether the pres-

Table 1

MCQ Subscale Means and Standard Deviations by Memory Category and Age Condition

\begin{tabular}{|c|c|c|c|c|c|c|c|c|c|c|c|c|c|}
\hline \multirow[b]{3}{*}{ MCQ Scale } & \multicolumn{6}{|c|}{ Adult } & \multicolumn{6}{|c|}{ Childhood } & \multirow{3}{*}{$\begin{array}{l}\text { Source of } \\
\text { Variation }\end{array}$} \\
\hline & \multicolumn{2}{|c|}{ Perceived } & \multicolumn{2}{|c|}{ Natural } & \multicolumn{2}{|c|}{ Guided } & \multicolumn{2}{|c|}{ Perceived } & \multicolumn{2}{|c|}{ Natural } & \multicolumn{2}{|c|}{ Guided } & \\
\hline & $M$ & $S D$ & $M$ & $S D$ & $M$ & $S D$ & $M$ & $S D$ & $M$ & $S D$ & $M$ & $S D$ & \\
\hline Clarity & 5.75 & 0.80 & 5.30 & 0.95 & 5.53 & 1.14 & 4.84 & 1.27 & 4.93 & 1.06 & 5.53 & 1.28 & $\mathrm{~A}>\mathrm{C}$ \\
\hline Sensory details & 3.59 & 1.47 & 2.57 & 1.20 & 2.71 & 1.09 & 3.02 & 1.55 & 2.58 & 1.36 & 3.03 & 1.21 & $\mathrm{P}>\mathrm{I}$ \\
\hline Contextual details & 6.06 & 0.90 & 4.81 & 1.56 & 5.62 & 0.93 & 5.57 & 1.25 & 4.61 & 1.63 & 5.15 & 1.36 & $P=G>I$ \\
\hline Temporal details & 5.85 & 1.08 & 4.06 & 1.82 & 4.06 & 1.69 & 3.68 & 1.37 & 3.48 & 1.02 & 3.83 & 1.41 & $\mathrm{P}>\mathrm{I}=\mathrm{G}(\mathrm{A}) ; \mathrm{A}>\mathrm{C}$ \\
\hline Thoughts/feelings & 4.33 & 0.89 & 5.06 & 0.89 & 4.15 & 1.18 & 4.16 & 1.42 & 4.56 & 1.37 & 4.01 & 1.42 & $I=P>G$ \\
\hline Intensity of feelings & 3.94 & 1.55 & 4.92 & 1.48 & 4.00 & 1.74 & 4.07 & 1.67 & 4.48 & 1.56 & 4.46 & 1.51 & \\
\hline Frequency of consideration & 3.14 & 1.68 & 4.43 & 1.71 & 2.14 & 1.59 & 3.02 & 1.61 & 3.54 & 1.81 & 2.15 & 1.04 & $\mathrm{I}>\mathrm{P}>\mathrm{G}$ \\
\hline
\end{tabular}


ent results replicated earlier findings (Johnson et al., 1988; McGinnis \& Roberts, 1996). Then, we compared guided imagery events with both perceived and natural imagery memories.

The 3 (memory type) $\times 2$ (age condition) ANOVAs indicated significant main effects of memory type for sensory detail $\left[F(2,96)=5.96, M S_{\mathrm{e}}=1.12, p=.004\right]$, contextual detail $\left[F(2,94)=9.54, M S_{\mathrm{e}}=1.59, p<.001\right]$, temporal detail $\left[F(2,96)=8.30, M S_{\mathrm{e}}=1.70, p<.001\right]$, thoughts and feelings $\left[F(2,94)=6.57, M S_{\mathrm{e}}=1.15, p=\right.$ $.002]$, and frequency of consideration $[F(2,96)=17.53$, $\left.M S_{\mathrm{e}}=2.42, p<.001\right]$. Main effects of age condition were also observed for clarity $\left[F(1,47)=4.91, M S_{\mathrm{e}}=1.36, p=\right.$ $.032]$, and temporal detail $\left[F(1,48)=13.32, M S_{\mathrm{e}}=2.77\right.$, $p=.001]$. In both of these cases, adult memories were rated higher than childhood memories. The interaction was also significant for temporal detail $[F(2,96)=7.86$, $\left.M S_{\mathrm{e}}=1.70, p=.001\right]$, because the effects of memory condition were significant in the adult condition, but not in the childhood condition (Table 1).

Perceived memories were rated higher than natural imagery memories in sensory detail (mean ratings of 3.32 and 2.58 for perceived and natural imagery memories, respectively; HSD $=.51$ ), contextual detail (mean ratings of 5.83 and 4.71 for perceived and natural imagery, respectively; HSD $=.61$ ), and temporal detail for the adult condition (adult means of 5.85 and 4.06 for perceived and natural imagery, respectively; HSD $=.77$ ) . Conversely, natural imagery memories had been considered more frequently than perceived memories (mean ratings of 3.08 and 4.00 for perceived and natural imagery, respectively; HSD $=.75$ ). These differences between phenomenal ratings of perceived and natural imagery memories support the predictions of the reality-monitoring framework and replicate previous findings (Johnson et al., 1988; McGinnis \& Roberts, 1996) in that memories of perceived events contained more sensory and contextual detail. As in previous studies, it appears that natural imagery events that are retrieved in this context are reviewed more frequently than the perceived memories (Johnson et al., 1988).

Guided imagery ratings differed from those of both natural imagery and perceived memories for the thoughts and feelings factor (means of 5.02, 5.27, and 4.50 for perceived, natural imagery, and guided imagery, respectively; HSD = .52), indicating that there were even fewer associated reflective memories for guided imagery than for perceived memories. Guided imagery also differed from both memory conditions in frequency of consideration (guided imagery mean $=2.14$ ), which is not surprising since the guided imagery was given immediately prior to the MCQ, so there was little opportunity for rehearsal of the event. Guided imagery ratings differed from those for natural imagery, but not perceived memories, for the factor of contextual detail (guided imagery mean $=5.40$ ). In contrast, in the adult condition for temporal detail, guided imagery ratings differed from perceived memories, but not natural imagery, (guided imagery mean $=4.06$ ). For the sensory detail factor, guided imagery did not significantly differ from either perceived or natural imagery memories, although it was marginally different from perceived memories (guided imagery mean $=2.87$ )

To summarize, reported phenomenal characteristics were the same for all three conditions for the factors of clarity and intensity of feelings. Guided imagery ratings were similar to those for perceived memories in contextual details, and were similar to those for natural imagery memories in temporal details, and marginally for sensory details. Memories for thoughts and feelings were fewer for guided imagery than for either perceived or natural imagery memories.

It might be argued that rating guided imagery in close proximity to rating a perceived memory might have induced greater comparison between representations than in normal reality-monitoring situations. To examine whether this influenced ratings for guided images, we conducted a post hoc analysis of order, comparing the ratings of participants who rated guided images prior to rating perceived memories with those who received the conditions in the reverse order. Means for this analysis are presented in Table 2. Ratings for each MCQ category except frequency of consideration were analyzed using a 2 (condition order) $\times 2$ (memory type: perceived or guided) ANOVA. If the availability of a perceived memory as a source of comparison influenced guided imagery ratings, this analysis would show significant order $X$ memory type interactions. However this interaction was nonsignificant for all relevant MCQ categories (largest $F=1.15$ ). It is also possible that the nonsignificant order interaction reflects adjustment of whichever ratings were completed second (i.e., deflating guided imagery ratings

Table 2

MCQ Subscale Means and Standard Deviations by Order of Perceived and Guided Imagery Conditions

\begin{tabular}{|c|c|c|c|c|c|c|c|c|c|c|}
\hline \multirow[b]{3}{*}{ MCQ Scale } & \multicolumn{4}{|c|}{ Perceived-Guided } & \multicolumn{4}{|c|}{ Guided-Perceived } & \multirow{3}{*}{$\begin{array}{c}\text { Order } \times \text { Condition } \\
F(1,48)\end{array}$} & \multirow{3}{*}{$\begin{array}{l}\text { Source of } \\
\text { Variation }\end{array}$} \\
\hline & \multicolumn{2}{|c|}{ Perceived } & \multicolumn{2}{|c|}{ Guided } & \multicolumn{2}{|c|}{ Perceived } & \multicolumn{2}{|c|}{ Guided } & & \\
\hline & $M$ & $S D$ & $M$ & $S D$ & $M$ & $S D$ & $M$ & $S D$ & & \\
\hline Clarity & 5.42 & 0.97 & 5.34 & 1.23 & 5.25 & 1.30 & 5.67 & 1.21 & 1.15 & \\
\hline Sensory details & 3.15 & 1.27 & 2.83 & 1.02 & 3.48 & 1.75 & 2.85 & 1.30 & 0.43 & $\mathrm{P}>\mathrm{G}(p=.053)$ \\
\hline Contextual details & 6.05 & 0.86 & 5.64 & 0.98 & 5.63 & 1.35 & 5.40 & 1.24 & 0.20 & \\
\hline Temporal details & 4.88 & 1.68 & 3.78 & 1.62 & 4.82 & 1.64 & 4.09 & 1.47 & 0.35 & $P>G$ \\
\hline Thoughts/feelings & 4.33 & 1.18 & 4.19 & 1.37 & 4.25 & 1.25 & 3.91 & 1.19 & 0.18 & \\
\hline Intensity of feelings & 3.91 & 1.54 & 4.20 & 1.59 & 4.17 & 1.67 & 4.22 & 1.69 & 0.16 & \\
\hline
\end{tabular}


relative to perceived ratings for the perceived-guided imagery order and inflating perceived ratings relative to guided imagery ratings for the reverse order). However, if such relative inflation or deflation of the second condition occurred, this would be evident in the means (Table 2), and would have resulted in a main effect of order (i.e., ratings for the perceived-guided imagery order would both be lower than for the guided imagery-perceived order). As this was not observed, we conclude that the order of conditions did not influence the ratings.

Guided imagery ratings did not differ from those for natural imagery memories in the factor of sensory detail, as would be expected if the attention to sensory detail in guided imagery were one of the factors that reduced the discriminability of guided imagery experiences and perceived events. To examine this issue more closely, we also analyzed the specific MCQ questions related to the various sensory modalities (MCQ Questions 2-7). For completeness, the questions related to vision (Questions 2 and 3 ) were included in this analysis, although they were not included with the sensory details factor in the above analyses. Question 3 was included in the clarity category for previous analyses (after McGinnis \& Roberts, 1996). The mean ratings for each sensory modality are shown in Figure 1 . These ratings were submitted to 3 (memory type) $\times 2$ (age condition) ANOVAs, which indicated main effects of memory type for the senses of sound $\left[F(2,96)=3.64, M S_{\mathrm{e}}=2.65, p=.030\right]$, smell $[F(2,96)=$ $\left.8.24, M S_{\mathrm{e}}=1.98, p<.001\right]$, touch $\left[F(2,96)=6.69, M S_{\mathrm{e}}=\right.$ $3.09, p=.002]$, and taste $\left[F(2,96)=5.02, M S_{\mathrm{e}}=1.62, p=\right.$ .008 ]. For all senses but touch, guided imagery ratings were significantly lower than those for perceived memories. For sound, the mean ratings for guided imagery
(3.64) did not differ from those for natural imagery events (3.62), and both were less than those for perceived events (4.40; HSD = .78). Similarly, for smell and taste, mean natural imagery and guided imagery ratings did not differ (means of 1.92 and 1.62 for smell; 1.40 and 1.56 for taste, for natural and guided imagery, respectively), but guided imagery differed significantly from perceived ratings (perceived means of 2.74 and 2.18; HSDs $=.68$ and .61 for smell and taste, respectively). Thus, for these specific sensory details, guided imagery experiences did not differ from memories for natural imagery events, but did differ from memories of perceived events. For the sense of touch, guided imagery ratings were significantly greater than those for natural imagery memories (means of 4.64 and 3.36 for guided and natural imagery, respectively; HSD $=.85$ ), and were also nominally larger than those for perceived events (mean of 3.94). Thus, the only sensory modality that matched the prediction that guided imagery events would be more similar to perceived memories in the degree of sensory information was the sense of touch.

\section{DISCUSSION}

This study replicated previous findings with respect to differences in phenomenal characteristics between perceived and natural imagery events (Johnson et al., 1988; McGinnis \& Roberts, 1996): Perceived memories were rated as having more sensory, contextual, and temporal detail than natural imagery memories. Guided imagery ratings were also lower than those for perceived memories for specific sensory details (i.e., sound, smell, and taste) and for temporal details, and these differences

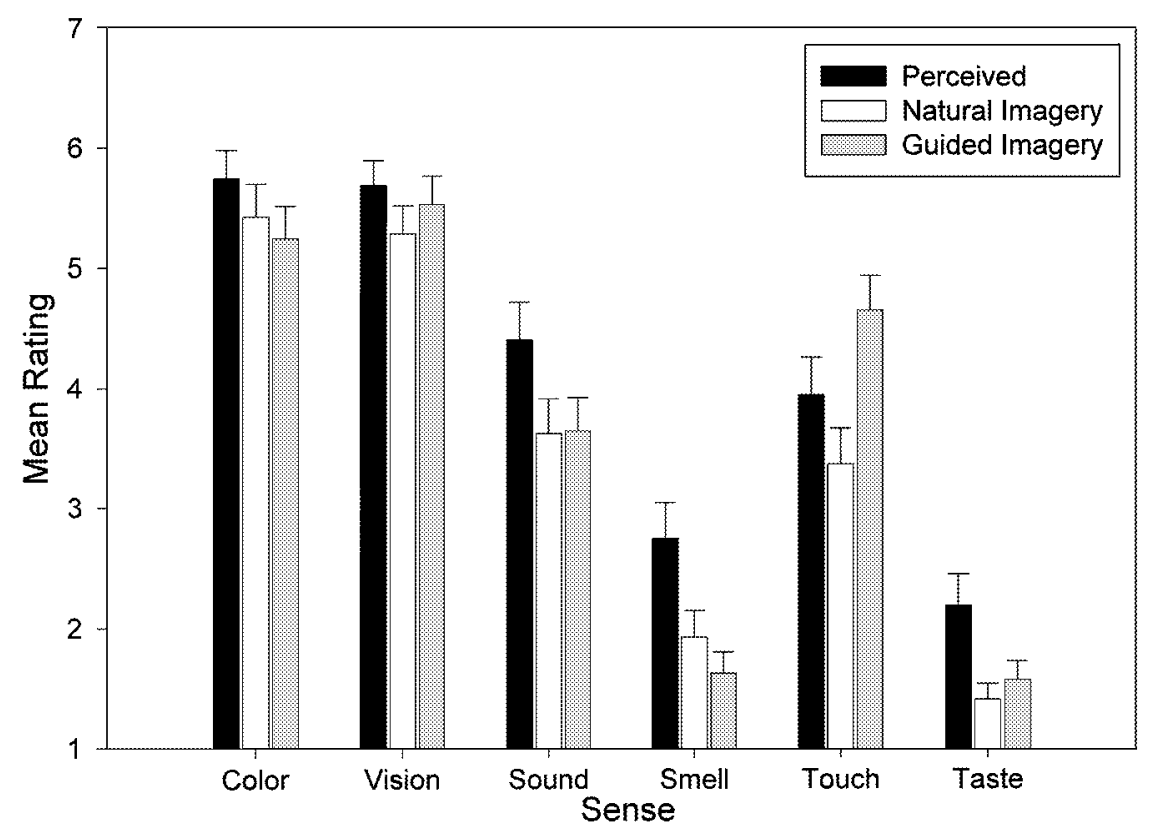

Figure 1. Mean MCQ sensory detail ratings, collapsed across age condition 
were observed whether participants rated guided imagery experiences before or after perceived memories, ruling out the recent examination of a perceived memory example as the relevant factor. Phenomenal ratings of guided imagery experiences were lower than both perceived and natural imagery memories for thoughts and feelings, consistent with our speculation that responding to guided imagery requires less reflective effort than natural imagery. Guided imagery ratings also indicated more contextual detail than for natural imagery memories, probably because context factors were specified in each of the guided imagery scripts. Overall, this pattern of findings suggests that the phenomenal characteristics of guided imagery representations were not especially similar to those for perceived memories, but neither were they typical of imagined memories (i.e., natural imagery) with respect to reflective details.

The finding that guided imagery events contained greater touch detail than either natural imagery or perceived memories (marginally for perceived) may have been related to the specific scripts that were used, each of which mentioned tactile contact (e.g., shaking hands with the prime minister, breaking a window with one's hand). However, the scripts also mentioned visual details (e.g., a crowd of excited people, a piece of paper in a parking lot) and sounds (e.g., a strange noise), and these sensory ratings were not greater in the guided imagery condition.Furthermore, although the prompts for natural imagery memories did not contain sensory suggestions, it is likely that at least one of the perceived memory themes would include a tactile component for many participants (i.e., visit to a dentist or doctor). Thus it is not clear why the touch sense discriminated guided imagery events in this way. Further research manipulating explicit suggestions of sensory details in both guided imagery scripts and memory prompts will be needed to clarify this potentially important finding.

The primary purpose of this study was to compare the phenomenal characteristics of memories for guided imagery, perceived events, and natural imagery in a single study, using a within-subjects design. Previous research has compared the rated phenomenology of perceived and imagined events, using either natural imagery (e.g., Johnson et al., 1988) or guided imagery (e.g., Suengas \& Johnson, 1988), but no study has examined both types of imagery. Concerns about misattributions relate more to guided imagery (e.g., suggested either by a therapist or by popular literature), but reality-monitoring processes are more likely to develop using natural imagery (e.g., children learning to distinguish between their dreams and waking events). Thus, the relative similarity of both types of imagery with perceived memories is important to examine. Consistent with our observation that guided imagery is intermediate on the internal-external source continuum, phenomenal ratings for guided imagery events were nominally intermediate to those of perceived and natural imagery memories for several factors (i.e., sensory and contextual details). However, ratings for guided imagery were lower than both natural imagery and perceived memories for reflective details (thoughts and feelings), suggesting that guided imagery may be atypical of the mentally generated class of memories with respect to this factor.

Although there was only one significant interaction between memory type and age condition, ratings were generally lower for the childhood condition. This suggests that phenomenal characteristics associated with childhood memories may be muted, and in two cases, this resulted in nominally higher ratings for guided imagery than for either perceived or imagined memories (i.e., clarity and intensity of feelings). Thus, it may be the case that phenomenal characteristics associated with memories from childhood provide a less reliable basis for reality-monitoring decisions, especially relative to recent guided imagery events (Stern \& Rotello, 2000). However, given the lack of statistical significance, this suggestion is made only speculatively.

A stronger conclusion from these results is that, in absolute terms, the phenomenal similarity of guided imagery and perceived memories is not inevitable (see also Heaps \& Nash, 2001; Suengas \& Johnson, 1988). Guided imagery events were rated as having qualitatively different characteristics from those of perceived memories, especially for the sensory details of sound, smell, and taste. However, guided imagery was rated nominally higher than perceived memories for touch details, so to use the presence of sensory details to support accurate reality monitoring, individuals would need to judge all senses in assessing their memories (i.e., cautious and broad-based reality-monitoring criteria). Given the theoretical possibility that guiding attention to imagined sensory experiences would influence this factor, this comparison between the three memory types needs to be replicated using guided imagery scripts with more specific references to sensory experience, such as scripts that are typical of those used in clinical and medical settings (Kunzendorf, 1990). However, at least when participants are encouraged to attend carefully to the characteristics of their memories, as would occur implicitly using the detailed MCQ, guided imagery representations appear to be associated with fewer sensory details than perceived memories, as has been observed for natural imagery.

However, phenomenal ratings of guided imagery differed from natural imagery with respect to thoughts and feelings and contextual details. If an individual considered these particular factors diagnostic of imagined events, he/she might misclassify a guided imagery event because the representation contained contextual details but few reflective details. The low ratings for thoughts and feelings accompanying a guided imagery experience is consistent with our assumption that responding to guided imagery is less mentally effortful than pursuing self-generated thoughts and fantasies, and thus produces fewer memories of reflective processes, but this may also 
render guided imagery memories less likely to be correctly identified as imagined. As discussed, the greater contextual detail associated with guided imagery ratings likely reflects the explicit use of context in the guided imagery scripts. However, the latter is also true of guided imagery scripts used in many clinical applications, and so explicit cautions about the nondiagnosticity of contextual details may be useful (see also Heaps \& Nash, 2001 , for evidence about the rated typicality of the events in false memory reports).

Given the practical importance of preventing misattributions of guided imagery, it would be valuable to clearly identify the factors that influence the likelihood of such misattributions. With respect to phenomenal similarity, three conditions that may result in guided imagery memory representations that are more similar to perceived memories remain to be investigated:(1) guided imagery scripts that focus more on sensory experiences than the present scripts, (2) consistent repetition of a guided imagery experience, and (3) delays between a guided imagery event and an attribution test. Heaps and Nash (2001) had participants review their image of a false event three times over the course of 3 weeks, and still observed discriminable memory ratings between true and false recollections. However, as they suggest, it is possible that a greater number of repetitions (i.e., rehearsals), combined with a longer delay, may result in guided imagery memory representations that are more similar to those for perceived memories. This issue is particularly important given the increased use of manualized psychotherapy treatments, which can result in considerable repetition across therapy sessions. Under the conditions of this study, guided imagery experiences were rehearsed less frequently than either perceived or natural imagery memories, because there was little opportunity for rehearsal of guided imagery experiences. The research of Suengas and Johnson (1988; see also Stern \& Rotello, 2000) suggests that guided imagery events may be forgotten more quickly than perceived events but that guided imagery memories also benefit more from rehearsal (including the rehearsal afforded by completing the MCQ immediately after the imagery experience). If under natural circumstances, guided imagery events are reviewed less frequently than either perceived or natural imagery events, this would presumably increase the difference between guided imagery and perceived memories even further over longer time periods. However, if a specific guided imagery script is rehearsed frequently, such as with manualized therapy approaches or uses of imagery to reduce stress or improve immune system function (Baum, Herberman, \& Cohen, 1995; Hall, 1990; Holden-Lund, 1988), differences between the guided imagery events and perceived memories could possibly decrease.

Research clearly indicates that guided imagery events can be mistaken for actual experiences under some circumstances. Although more research is needed to iden- tify the relevant circumstances, it is also timely to begin investigating the causal mechanisms of these effects. The results of this study provide initial evidence that memory representations of guided imagery and autobiographical events are not inevitably similar with respect to sensory details, but that guided imagery representations are dissimilar from natural imagery with respect to reflective details. Further research is needed to determine whether phenomenal characteristics of perceived memories and guided imagery would be more similar with guided imagery scripts that focus attention to sensory experiences more strongly, or with repeated experience of a single guided imagery script.

\section{REFERENCES}

Arbuthnott, K. D., Arbuthnott, D. W., \& Rossiter, L. (2001). Guided imagery and memory: Implications for psychotherapists. Journal of Counseling Psychology, 48, 123-132.

Baum, A., Herberman, H., \& Cohen, L. (1995). Managing stress and managing illness: Survival and quality of life in chronic disease. Journal of Clinical Psychology in Medical Settings, 2, 309-333.

BinK, M. L., MARSH, R. L., \& HicKs, J. L. (1999). An alternative conceptualization to memory "strength" in reality monitoring. Journal of Experimental Psychology: Learning, Memory, \& Cognition, 25, 804-809.

Brown, D., Scheflin, A. W., \& Hammond, D. C. (1998). Memory, trauma treatment, and the law. New York: W. W. Norton.

CECI, S. J., \& Loftus, E. F. (1994). "Memory work": A royal road to false memories? Applied Cognitive Psychology, 8, 351-364.

Durso, F. T., \& Johnson, M. K. (1980). The effects of orienting tasks on recognition, recall, and modality confusion of pictures and words. Journal of Verbal Learning \& Verbal Behavior, 19, 416-429.

Finke, R. A., Johnson, M. K., \& Shyi, G. C.-W. (1988). Memory confusions for real and imagined completions of symmetrical visual patterns. Memory \& Cognition, 16, 133-137.

Garry, M., Manning, C. G., Loftus, E. F., \& Sherman, S. J. (1996). Imagination inflation: Imagining a childhood event inflates confidence that it occurred. Psychonomic Bulletin \& Review, 3, 208-214.

Garry, M., \& Polaschek, D. L. L. (2000). Imagination and memory. Current Directions in Psychological Science, 9, 6-10.

Goff, L. M., \& Roediger, H. L., III (1998). Imagination inflation for action events: Repeated imaginings lead to illusory recollections. Memory \& Cognition, 26, 20-33.

HALL, H. (1990). Imagery, psychoneuroimmunology, and the psychology of healing. In R. G. Kunzendorf \& A. A. Sheikh (Eds.), The psychophysiology of mental imagery: Theory, research, and application (pp. 203-227). Amityville, NY: Baywood.

HEAPS, C., \& NASH, M. (1999). Individual differences in imagination inflation. Psychonomic Bulletin \& Review, 6, 313-318.

HeAPS, C., \& NASH, M. (2001). Comparing recollective experience in true and false autobiographical memories. Journal of Experimental Psychology: Learning, Memory, \& Cognition, 27, 920-930.

Henkel, L. A., Franklin, N., \& Johnson, M. K. (2000). Cross-modal source monitoring confusions between perceived and imagined events. Journal of Experimental Psychology: Learning, Memory, \& Cognition, 26, 321-335.

Holden-Lund, C. (1988). Effects of relaxation with guided imagery on surgical stress and wound healing. Research in Nursing \& Health, 11, 235-244.

Hyman, I. E., \& Pentland, J. (1996). The role of mental imagery in the creation of false childhood memories. Journal of Memory \& Language, 35, 101-117.

JoHNSON, M. K. (1991). Reflection, reality monitoring, and the self. In R. G. Kunzendorf(Ed.), Mental imagery (pp. 3-16). New York: Plenum.

Johnson, M. K., Foley, M., Suengas, A. G., \& Raye, C. L. (1988). Phenomenal characteristics of memories for perceived and imagined 
autobiographical events. Journal of Experimental Psychology: General, 117, 371-376.

Johnson, M. K., Hashtroudi, S., \& Lindsay, D. S. (1993). Source monitoring. Psychological Bulletin, 114, 3-28.

Johnson, M. K., Kahan, T. L., \& RaYe, C. L. (1984). Dreams and reality monitoring. Journal of Experimental Psychology: General, 113, 329-344.

Johnson, M. K., \& RaYe, C. L. (1981). Reality monitoring. Psychological Review, 88, 67-85.

Johnson, M. K., Raye, C. L., WANG, A. Y., \& Taylor, T. H. (1979). Fact and fantasy: The roles of accuracy and variability in confusing imaginations with perceptual experience. Journal of Experimental Psychology: Human Learning \& Memory, 5, 229-240.

KunZENDORF, R. G. (ED.) (1990). Mental imagery. New York: Plenum.

LindSAY, D. S., \& BRIERE, J. (1997). The controversy regarding recovered memories of childhood sexual abuse: Pitfalls, bridges, and future directions. Journal of Interpersonal Violence, 12, 631-647.

LindSAY, D. S., \& READ, J. D. (1994). Psychotherapy and memories of childhood sexual abuse: A cognitive perspective. Applied Cognitive Psychology, 8, 281-338.

LofTus, E. F. (1997, September). Creating false memories. Scientific American, pp. 70-75.

Mather, M., Henkel, L. A., \& Johnson, M. K. (1997). Evaluating characteristics of false memories: Remember/know judgments and memory characteristics questionnaire compared. Memory \& Cognition, 25, 826-837.

McGinnis, D., \& Roberts, P. (1996). Qualitative characteristics of vivid memories attributed to real and imagined experiences. American Journal of Psychology, 109, 59-77.

Mrtchell, K. J., \& Johnson, M. K. (2000). Source monitoring: Attributing mental experiences. In E. Tulving \& F. I. M. Craik (Eds.), The Oxford handbook of memory (pp. 179-195). Oxford: Oxford University Press.
Mitchell, K. J., \& Zaragoza, M. S. (1996). Repeated exposure to suggestion and false memory: The role of contextual variability. Journal of Memory \& Language, 35, 246-260.

Pezdek, K., \& Hodge, D. (1999). Planting false childhood memories in children: The role of event plausibility. Child Development, 70, 887-895.

Shobe, K. K., \& Schooler, J. W. (in press). Discovering fact and fiction: Case based analyses of authentic and fabricated discovered memories of abuse. In G. Davies \& T. Dalgleish (Eds.), Recovered memories: Seeking the middle ground. Chichester, U.K.: Wiley.

Stern, E. R., \& Rotello, C. M. (2000). Memory characteristics of recently imagined events and real events experienced previously.American Journal of Psychology, 113, 569-590.

Suengas, A. G., \& Johnson, M. K. (1988). Qualitative effects of rehearsal on memories for perceived and imagined complex events. Journal of Experimental Psychology: General, 117, 377-389.

\section{NOTES}

1. "The Secret Life of Walter Mitty," by James Thurber, related the story of a man who lived a very mundane actual life, but who had a very rich fantasy life involving many adventures featuring himself as a hero.

2. Judgment criteria, decisions about which characteristics are diagnostic or about thresholds of characteristic differentiation, are also clearly important for source monitoring (e.g., Bink, Marsh, \& Hicks, 1999). However, if the phenomenal characteristics of different classes of memories (i.e., originally perceived or imagined events) are not discriminable even at encoding, even optimal source-monitoring criteria will have little influence on attribution accuracy. Similarly, the retrieval cues used to access memory representations are also important (Mitchell \& Johnson, 2000; Mitchell \& Zaragoza, 1996), but if encoded representations are not discriminable, the probability of retrieving qualitatively different representations is also severely limited.

\section{APPENDIX A \\ Stimuli for the Memory Characteristics Questionnaire Task}

\section{Perceived Events}

1. Visit to a library: Think of a recent time you spent in a library.

2. Visit to a doctor/dentist: Think of a recent time you visited the doctor or dentist.

3. Social occasion: Think of a recent social occasion—party, dinner, or a gathering of some sort - that involved more than two people including yourself.

\section{Imagined Events}

1. Fantasy: Think of a recent fantasy - that is, something you made up and imagined while you were awake-any fantasy you can remember fairly well.

2. Dream: Think of a recent dream — any dream you can remember fairly well.

3. Unfulfilled intention: Think of a recent time you intended to do or thought about doing something, but then never got around to doing it. It should be something that you actually might have done but did not.

\section{Guided Imagery}

\section{Shaking hands with the prime minister:}

Setting: Imagine that you are at the legislative building. You notice a crowd of excited people, so you go over to see what is going on. The prime minister of Canada just happens to be visiting. One of his aides tells everyone that if they get into a line, the prime minister will shake their hands. You decide to wait in line. (Question: Where were you in the line?)

Action: As you wait, you watch the prime minister shake the hands of the people ahead of you in line. The prime minister finally gets to you. (Question: What happens next?)

\section{Finding $\$ 10$ :}

Setting: Imagine that it is the weekend and you have just been shopping with someone. (Question: What store or mall were you shopping in and who were you with?)

Action: As you are walking through the parking lot to collect your car a piece of paper catches your attention. You think it might be money. You reach down and pick it up. It is a $\$ 10$ bill. (Question: What are you likely to do next?) 
APPENDIX A (Continued)

3. Breaking window:

Setting: Imagine that it is after work (or University) and you are relaxing in your home. You hear a strange noise outside, so you rush to the window to see what made the noise. As you are rushing, your foot catches on something and you trip and fall. (Question: What did you trip on?)

Action: As you are falling, you reach out to catch yourself and your hand goes through the window. As the window breaks you get cut and there is some blood. (Question: What are you likely to do next?)

These instructions and scripts are for the adult condition. They were revised appropriately for participants who were asked to remember and imagine childhood events.

\section{APPENDIX B \\ Memory Characteristics Questionnaire Items}

1. My memory for this event is: dim / clear

2. My memory for this event is: black and white / entirely color

3. My memory for this event involves visual detail: little or none / a lot

4. My memory for this event involves sound: little or none / a lot

5. My memory for this event involves smell: little or none / a lot

6. My memory for this event involves touch: little or none / a lot

7. My memory for this event involves taste: little or none / a lot

8. Overall vividness is: vague / very vivid

9. My memory for this event is: sketchy/very detailed

10. Order of events is: confusing/ comprehensive

11. Story line is: simple / complex

12. Story line is: bizarre / realistic

13. My memory for the location where the event takes place is: vague / clear and distinct

14. General setting is: unfamiliar / familiar

15. Relative spatial arrangement of objects in my memory for this event is: vague / clear and distinct

16. Relative spatial arrangement of people in my memory for this event is: vague / clear and distinct

17. My memory for the time when the event takes place is: vague / clear and distinct

18. My memory for the year when the event takes place is: vague / clear and distinct

19. My memory for the season when the event takes place is: vague / clear and distinct

20. My memory for the day when the event takes place is: vague / clear and distinct

21. My memory for the hour when the event takes place is: vague / clear and distinct

22. The event seems: short / long

23. The overall tone of the memory is: negative/ positive

24. In this event I was a: spectator/participant

25. At the time, the event seemed like it would have serious implications: not at all / definitely

26. Looking back, the event did have serious implications: not at all / definitely

27. I remember how I felt at the time when the event took place: not at all / definitely

28. Feelings at the time were: negative/ positive

29. Feelings at the time were: not intense / very intense

30. As I am remembering now, my feelings are: not intense / very intense

31. I remember what I thought at the time: not at all / clearly

32. This memory reveals or says about me: not much / a lot

33. Overall, I remember this event: hardly / very well

34. I remember events relating to this memory that took place in advance of the event: not at all / clearly

35. I remember events relating to this memory that took place after the event: not at all / clearly

36. Do you have any doubts about the accuracy of your memory for this event? A great deal of doubt / no doubt whatsoever

37. Since it happened, I have thought about this event: not at all / many times

38. Since it happened, I have talked about it: not at all / many times

39. About when did this event happen? Just today, yesterday, a few days ago, last week, a few weeks ago, last month, a few months ago, last year, longer

Note-All items are 7-point scales. 


\section{APPENDIX C \\ Questions in the Memory Characteristics Questionnaire Subscales}

1. Clarity: Questions 1, 3, 8, 9, 33**

2. Sensory details: Questions $4-7^{* *}$

3. Contextual details: Questions 13,15,16*

4. Temporal details: Questions 17-21**

5. Thoughts and feelings: Questions $27,31,32^{*}$

6. Intensity of feelings: Questions 29, 30*

7. Frequency of consideration: Questions $37,38^{* *}$

Note-Subscale scores were determined by calculating the mean for each set of questions. *Previously used in Suengas and Johnson (1988). ${ }^{* *}$ Previously used in McGinnis and Roberts (1996).

(Manuscript received December 19, 2000;

revision accepted for publication January 15,2002 .) 